\title{
Pulmonary melioidosis in Cambodia: A prospective study
}

\author{
Blandine Rammaert ${ }^{1}$, Julien Beauté ${ }^{1}$ Laurence Borand ${ }^{1}$, Sopheak Hem¹, Philippe Buchy ${ }^{1}$, Sophie Goyet ${ }^{1}$, \\ Rob Overtoom², Cécile Angebault ${ }^{1}$, Vantha Te ${ }^{3}$, Patrich Lorn Try ${ }^{4}$, Charles Mayaud ${ }^{5}$, Sirenda Vong ${ }^{1 *}$ and \\ Bertrand Guillard ${ }^{1}$
}

\begin{abstract}
Background: Melioidosis is a disease caused by Burkholderia pseudomallei and considered endemic in South-East Asia but remains poorly documented in Cambodia. We report the first series of hospitalized pulmonary melioidosis cases identified in Cambodia describing clinical characteristics and outcomes.

Methods: We characterized cases of acute lower respiratory infections (ALRI) that were identified through surveillance in two provincial hospitals. Severity was defined by systolic blood pressure, cardiac frequency, respiratory rate, oxygen saturation and body temperature. B. pseudomallei was detected in sputum or blood cultures and confirmed by API20NE gallery. We followed up these cases between 6 months and 2 years after hospital discharge to assess the cost-of-illness and long-term outcome.

Results: During April 2007 - January 2010, 39 ALRI cases had melioidosis, of which three aged $\leq 2$ years; the median age was 46 years and $56.4 \%$ were males. A close contact with soil and water was identified in 30 patients (76.9\%). Pneumonia was the main radiological feature (82.3\%). Eleven patients were severe cases. Twenty-four (61.5\%) patients died including 13 who died within 61 days after discharge. Of the deceased, 23 did not receive any antibiotics effective against B. pseudomallei. Effective drugs that were available did not include ceftazidime. Mean total illness-related costs was of US\$65 (range \$25-\$5000). Almost two-thirds (61.5\%) incurred debt and 28.2\% sold land or other belongings to pay illness-related costs.

Conclusions: The observed high fatality rate is likely explained by the lack or limited access to efficient antibiotics and under-recognition of the disease among clinicians, which led to inappropriate therapy.
\end{abstract}

Keywords: Burkholderia pseudomallei community-acquired pneumonia, tuberculosis, Cambodia

\section{Background}

Melioidosis is an infectious disease due to non-saprophytic Gram-negative bacillus Burkholderia pseudomal$l e i$, which can be found in wet soil and surface water [1]. Endemic areas encompass Southeast Asia and Northern Australia demonstrating seasonality with more cases detected/reported during the rainy season [2,3]. In addition to contact with an environmental exposure, underlying conditions pre-disposing for the disease include diabetes mellitus, alcohol abuse, chronic lung disease and chronic renal disease [1,4]. The three main routes of contamination are cutaneous inoculation,

\footnotetext{
* Correspondence: sirenda.vong@gmail.com

'Institut Pasteur - Cambodia, Phnom Penh, Cambodia

Full list of author information is available at the end of the article
}

inhalation and ingestion [5]. Presentation of the disease is highly variable ranging from acute septicemia to chronic localized abscess while most infections with $B$. pseudomallei are asymptomatic [6]. Lungs are the most commonly infected organs but every organ may be affected. Other frequent localizations include skin abscess, osteomyelitis, arthritis, prostatic and parotids abscesses $[1,7,8]$. Diagnosis of melioidosis relies on the isolation of B. pseudomallei in clinical samples (mostly blood, sputum and pus). Serology is useful for epidemiological surveys but of little diagnostic interest since most of the population is sero-positive in endemic areas [9]. Analysis of resistance patterns of the B. pseudomalle $i$ strains showed that severe cases of melioidosis were best treated with at least 10 days of intravenous

\section{Biomed Central}


intensive therapy with ceftazidime followed by 12 to 20 weeks of an oral eradication therapy using a three-drug regimen (i.e. trimethoprim-sulfamethoxazole and doxycycline) $[5,10]$. Outcome depends on both severity of cases and the level of health services. Septicemia and acute pulmonary forms are the most severe with fatality rates as high as $40 \%$, despite appropriate treatment [1].

Melioidosis remains poorly documented in many countries of the endemic areas [4]. This applies to Cambodia where first indigenous cases were recently reported [11-13]. A study in Siem Reap province reported the detection of antibodies against $B$. pseudomallei in $16 \%$ of Cambodian children and isolation in $30 \%$ of the surrounding rice fields, which indicates high exposure to the pathogen [14].

This report summarizes the characteristics of pulmonary melioidosis cases among patients hospitalized with acute lower respiratory infection and the results of a follow-up investigation of these cases several months after hospital discharge.

\section{Methods}

In April 2007, we implemented surveillance of acute lower respiratory infections (ALRI) in two Cambodian provincial hospitals (Takeo, Southern province and Kampong Cham, Eastern province) combined with identification of bacterial and viral etiologies. Four adult (Internal Medicine, Infectious Disease, Intensive Care) and two Pediatric wards participated in the surveillance study. Eligibility criteria for ALRI included symptoms onset $\leq 14$ days, fever $\geq 38^{\circ} \mathrm{C}$ or a history of febrile episodes within the previous 3 days, recent cough, plus at least one of the following respiratory symptoms: dyspnea, chest pain or crackles on lung auscultation. Patients with known tuberculosis (TB), or known acquired immunodeficiency such as HIV, chronic corticosteroids use and cancer were excluded.

For each participant, hospital clinicians were asked to complete a standardized surveillance form, including information on patient's medical history, clinical features, treatment, laboratory and radiological findings and patients' outcome at discharge. A chest X-ray was requested for each enrolled patient within 24 hours from admission; blood tests (i.e. complete blood cells count, glycemia, liver enzymes, blood creatinine levels and serum electrolytes) and sputum smear microscopy for acid-fast bacilli detection were performed on site. The surveillance forms and chest X-rays were retrospectively reviewed by an expert pulmonologist.

Blood and sputum were sent daily to the Institut Pasteur - Cambodia (IPC) for culture and antibiotic susceptibility testing (AST). B. pseudomallei was cultured from sputum on Drigalski and Ashdown's agar and identified by API20NE gallery (BioMérieux). Blood sample was taken on Hemoline Diphasic Performance bottle (BioMérieux) for adults and Isolator 1.5 (Oxoid) $(1.5 \mathrm{ml})$ for children. We determined antimicrobial drug susceptibility by the disk-diffusion method on Mueller-Hinton agar plates (Bio-Rad). When B. pseudomallei appeared resistant to cotrimoxazole, Minimum inhibitory concentrations were determined using the E-test diffusion method (AB Biodisk) to confirm or infirm resistance [1]. Bacteriology results were returned to the patient's clinicians as soon as they were available, together with AST.

\section{The follow-up investigation}

For the purpose of the study, we visited and interviewed all confirmed melioidosis cases at home within six months after hospital discharge to assess the patient's status and collect additional information using a standardized questionnaire. We collected information regarding known risk factors for melioidosis (i.e. previous pulmonary disease or history of smoking, diabetes mellitus, chronic disease, alcohol intake, repeated contact with wet soils), medical history of infection, wounds or abscesses, time to diagnosis, disease evolution, date of death if appropriate, and economic burden on patients' families. Patients were visited a second time between 6 months and 2 years after the first home visit to follow-up on possible relapse.

\section{Definitions}

A pulmonary melioidosis case was defined as a patient with a febrile illness and respiratory symptoms with the identification of B. pseudomallei in sputum and/or blood culture. A severe case was defined by the presence of at least two of the following criteria: systolic blood pressure $<90 \mathrm{mmHg}$, cardiac frequency $\geq 120$ beats-per-minute, respiratory rate $\geq 30 / \mathrm{mn}$, oxygen saturation $<90 \%$, temperature $<35^{\circ} \mathrm{C}$ or $\geq 40^{\circ} \mathrm{C}$. For children, severity was assessed using the World Health Organization criteria [15]. In the present study, we defined chronic forms of melioidosis when re-assessment (follow-up investigation) of patient's medical history revealed onset of symptoms $>14$ days. Since no patient was taking anti-diabetic drug, we retained as diabetic every patient with glycemia $>126$ $\mathrm{mg} / \mathrm{dL}$ or a history of diabetes mellitus. Chronic lung disease includes chronic bronchitis and pre-existing pulmonary lesions. Renal impairment was defined by serum creatinine levels $>2 \mathrm{mg} / \mathrm{dL}$. A necrotizing pneumonia was defined by the presence of radiographic imaging of either cavity or abscess, unique or multiple.

\section{Treatment}

Antibiotics that are effective against B. pseudomallei and available in Takeo and Kampong Cham include sulfamethoxazol-trimethoprime (cotrimoxazole), chloramphenicol, doxycycline, co-amoxiclav. The standard 
treatment protocol was based on the Thai guidelines, 22 weeks of a four-antibiotic regimen including cotrimoxazole, chloramphenicol and doxycycline. If the patient's condition had significantly improved on week 8 of treatment, chloramphenicol would be discontinued [1]. An out-patient follow-up was implemented at each hospital during and after the treatment.

\section{Ethics}

The surveillance study was approved by the Cambodian National Ethical Committee. All patients/parents of sick children who participated in surveillance provided written informed consent.

\section{Statistical methods}

Statistical analyses were performed using Stata version 9.0 (Statacorp, College Station, TX, USA). Continuous variables were presented with their median (minimum and maximum ranges) or with their mean and standard deviation. Variables were compared across groups using the Wilcoxon-Mann-Whitney test for continuous variables, and the Chi-square or Fisher's exact test for categorical variables. For all analyses, statistical significance was defined as $P<0.05$.

\section{Results}

Patients' characteristics

From April 2007 to February 2010, 2,840 patients with ALRI (i.e. pneumonia, abscess, pleural effusion, superinfection on lung sequelae, bronchitis) were reported through surveillance and 2,407 had at least one sample available (1,985 in Takeo and 422 in Kampong Cham) for bacteriological testing. Among these patients with ALRI, 39 (1.6\%) were confirmed as having been infected by B. pseudomallei, of which 35 were treated at Takeo and 4 at Kampong Cham hospital; the proportion of $B$. pseudomallei isolates among positive cultures was 9.3\% including $51.4 \%$ in blood culture and $7.7 \%$ in sputum culture. The demographics and baseline characteristics of patients are presented in Table 1 . The median age on admission was 46 years (range 1 month - 74 years). Among the 39 patients, 3 were children of which one was less than two months old. Two adults had a history of near-drowning. Underlying conditions identified as a risk factor were reported in 23 (59.0\%) patients (Table 1). Among these 23 patients, 7 had diabetes mellitus and one tested positive for HIV antibodies. A soil exposure or close contact with water was identified in $30(76.9 \%)$ patients. All of them reported working in rice fields and some reported additional activities such as fishing, collecting water plants or working in construction. One patient was pregnant, but her pregnancy term could not be ascertained.

\section{Clinical and microbiological diagnosis}

Of the reported cases, 15 were confirmed by sputum culture, 18 by blood culture and 6 by both. In-depth interviews during the follow-up investigation actually

Table 1 General characteristics of the $\mathbf{3 9}$ melioidosis cases

\begin{tabular}{|c|c|c|c|c|}
\hline & $\begin{array}{l}\text { All patients } \\
(\mathrm{n}=39)\end{array}$ & $\begin{array}{l}\text { Non severe } \\
(\mathrm{n}=28)\end{array}$ & $\begin{array}{l}\text { Severe } \\
(\mathrm{n}=11)\end{array}$ & $P$ value \\
\hline Male & $22(56.4 \%)$ & $19(67.9 \%)$ & $3(27.3 \%)$ & 0.03 \\
\hline Age, median years (min. - max.) & $46(0.08-74)$ & $47.5(19-72)$ & $29(0.08-74)$ & \\
\hline \multicolumn{5}{|l|}{ Risk factors } \\
\hline Close contact with wet soil & $30(76.9 \%)$ & $23(82.1 \%)$ & $7(63.6 \%)$ & \\
\hline Underlying chronic disease & $23(59.0 \%)$ & $21(75.0 \%)$ & $2(18.2 \%)$ & $<0.01$ \\
\hline Diabetes mellitus & $7(18.0 \%)$ & $7(25.0 \%)$ & & \\
\hline Renal impairment & $4(10.3 \%)$ & $3(10.7 \%)$ & $1(9.1 \%)$ & \\
\hline Chronic lung disease & $13(33.3 \%)$ & $12(42.6 \%)$ & $1(9.1 \%)$ & \\
\hline Alcoholism & $12(30.8 \%)$ & $10(35.7 \%)$ & $2(22.2 \%)$ & \\
\hline \multicolumn{5}{|l|}{ Data on admission } \\
\hline Temperature $\geq 38^{\circ} \mathrm{C}$ & $27(69.2 \%)$ & $17(60.7 \%)$ & $10(90.9 \%)$ & \\
\hline Cough & 38 (97.4\%) & 27 (96.4\%) & $11(100 \%)$ & \\
\hline Dyspnea & $30(76.9 \%)$ & $21(75.0 \%)$ & $9(81.8 \%)$ & \\
\hline Thoracic pain & $31(79.5 \%)$ & $26(92.9 \%)$ & $5(45.5 \%)$ & $<0.01$ \\
\hline Hemoptysis & $1(2.6 \%)$ & $1(3.7 \%)$ & & \\
\hline Leucocytes median $10^{3} / \mathrm{mm}^{3}$ & $9.4(6.5-14.4)$ & $10.9(7.6-16.6)$ & $6.4(3.2-9.4)$ & $<0.01$ \\
\hline Pneumonia & 27/34 (79.4) & 20/27 (74.0) & $7 / 7(100)$ & \\
\hline Pleural effusion & $2 / 28(7.1 \%)$ & $2 / 27(7.4 \%)$ & & \\
\hline \multicolumn{5}{|l|}{ Outcome } \\
\hline Death & 24/39 (61.5\%) & 13/15 (46.4\%) & $11 / 11(100)$ & $<0.01$ \\
\hline Time to death, days (min-max) & $3(1-61)$ & $3(1-61)$ & $3(1-14)$ & \\
\hline
\end{tabular}


identified $15(38.5 \%)$ cases that had symptoms onset beyond 14 days (median 30 days, range 21 days - 3 years); onset of symptoms could not be ascertained for four patients. Eleven (28.2\%) patients including all pediatric cases were severe. None of the two patients with history of near drowning was severe on admission. Twenty-eight $(71.8 \%)$ were identified during the rainy season (from May to October). Detailed clinical and laboratory data are presented in Table 1. Productive cough was present in $28(71.8 \%)$ cases. One patient had hemoptysis without cavity on chest radiography. Leucocytes count was significantly higher in acute melioidosis $(14.3 \%$ vs. $8.5 \% ; p<0.01)$ and in non-severe cases ( $10.9 \%$ vs. $6.4 \%$; $<$ < 0.01$)$. Liver enzymes level did not significantly differ between severe/non-severe cases or acute/chronic forms.

A positive blood culture was significantly associated with severe cases $(10 / 11$ vs. $14 / 26 ; \mathrm{p}=0.03)$. Although $5 / 7$ (71.4\%) diabetic patients had positive blood culture, none was severe. No patient had bacterial co-infection; however, two of the 3 children had H3N2 influenza A virus infection. Bacteriological results and B. pseudomallei sensitivity to main antibiotics are displayed in Tables 2 and 3 . All the strains were susceptible to cotrimoxazole with E-test method, although 20 (51.3\%) were not susceptible with disk-diffusion method.

\section{Radiological features}

Chest radiographs were only available in 34 (87.2\%) cases (Table 4). Of these, 5 patients had no evidence of pneumonia or pleural effusion, 2 only had pleural effusions and $27(79.4 \%)$ had pneumonia associated with abscesses, nodules or pleural effusions; 16 (59.3\%) pneumonia consisted of pulmonary lesions in two or more lobes. All severe melioidosis cases for which chest radiographs were available showed evidence of pneumonia with either alveolar consolidation $(n=2)$, nodules $(n=$ 3 ) or pleuropneumonia $(n=2)$. Two patients who had normal chest radiographs tested positive for $B$.

Table 2 Types of bacteriological results from melioidosis cases

\begin{tabular}{|c|c|c|c|c|}
\hline & $\begin{array}{l}\text { All } \\
\text { patients } \\
(n=39)\end{array}$ & $\begin{array}{l}\text { Non } \\
\text { severe } \\
(n=28) \\
\end{array}$ & $\begin{array}{l}\text { Severe } \\
(n=11)\end{array}$ & $\begin{array}{l}P \\
\text { value }\end{array}$ \\
\hline \multicolumn{5}{|l|}{ Source of isolates } \\
\hline Sputum & $\begin{array}{l}21 / 22 \\
(95.5 \%)\end{array}$ & $\begin{array}{l}19 / 20 \\
(95.0 \%)\end{array}$ & $2 / 2(100 \%)$ & \\
\hline Blood culture & $\begin{array}{l}24 / 37 \\
(64.9 \%)\end{array}$ & $\begin{array}{l}14 / 26 \\
(53.8 \%)\end{array}$ & $\begin{array}{l}10 / 11 \\
(90.9 \%)\end{array}$ & 0.03 \\
\hline $\begin{array}{l}\text { Sputum and blood } \\
\text { culture }\end{array}$ & $6(15.4 \%)$ & $5(17.9 \%)$ & 1 (9.1\%) & \\
\hline $\begin{array}{l}\text { Resistant strains to } \\
\text { co-amoxiclav }\end{array}$ & $5(13.5 \%)$ & $3(11.5 \%)$ & $2(18.2 \%)$ & \\
\hline
\end{tabular}

Table 3 In vitro activities of selected antibiotics against 39 strains of $B$. pseudomallei

\begin{tabular}{llll}
\hline Agent & Sensitive & Intermediate & Resistant \\
\hline Amoxicillin-clavulanate & $32(82.1 \%)$ & $2(5.1 \%)$ & $5(12.8 \%)$ \\
Aztreonam & $29(74.4 \%)$ & $10(25.6 \%)$ & \\
Ceftazidime & $39(100 \%)$ & & $1(2.6 \%)$ \\
Chloramphenicol & $38(97.4 \%)$ & & \\
Cotrimoxazole* & $39(100 \%)$ & & \\
Imipenem & $39(100 \%)$ & & \\
Piperacillin & $39(100 \%)$ & $1(2.6 \%)$ & \\
Piperacillin-tazobactam & $39(100 \%)$ & $1(2.6 \%)$ & $35(89.7 \%)$ \\
Tetracyclin & $38(94.8 \%)$ & $1(2.6 \%)$ & $12(30.8 \%)$ \\
Ticarcillin & & $4(10.3 \%)$ & $15(38.4 \%)$ \\
Ticarcillin-clavulanate & $12(30.8 \%)$ & 12 & \\
\hline
\end{tabular}

*Susceptibility testing was done by diffusion disk method for all antibiotics. Etest method was only used to detect resistance to cotrimoxazole

pseudomallei by blood culture. Pulmonary sequelae were found on 3 chest radiographs including emphysema, probable TB sequelae and bronchiectasis relatedpost-infection. Interestingly the experts panel interpreted chest radiographs of five cases of melioidosis as TB-like (Figure 1); all but one were negative for acidfast bacilli (AFB) by direct sputum examination (in line with the national TB program, AFB negative pneumonias evocative of TB are not systematically cultured). Three of these five cases had chronic melioidosis.

\section{Treatment and outcome}

Only 13 patients (none were severe) received antibiotics active against $B$. pseudomallei either during hospitalization or after discharge. The mean duration of hospitalisation was 6 days (range 1 - 11 days) with a shorter duration for severe patients (2 days [1-4] vs 8 [2-12];

Table 4 Radiographic features on acute and and chronic melioidosis cases' chest X-rays

\begin{tabular}{|c|c|c|c|}
\hline & $\begin{array}{l}\text { All } \\
\text { patients } \\
\left(\mathrm{n}=34^{*}\right)\end{array}$ & $\begin{array}{l}\text { Patients with } \\
\text { acute } \\
\text { melioidosis } \\
(\mathrm{n}=19)\end{array}$ & $\begin{array}{l}\text { Patients with } \\
\text { chronic } \\
\text { melioidosis } \\
(\mathrm{n}=13)\end{array}$ \\
\hline Pneumonia** & $\begin{array}{l}27 \\
(79.4 \%)\end{array}$ & $13(68.4 \%)$ & $12(92.3 \%)$ \\
\hline Necrotizing & $\begin{array}{l}10 \\
(29.4 \%)\end{array}$ & $6(31.6 \%)$ & $4(30.8 \%)$ \\
\hline Nodular & $5(17.9 \%)$ & $1(5.3 \%)$ & $2(15.4 \%)$ \\
\hline With pleural effusion & $4(11.8 \%)$ & $1(5.3 \%)$ & $3(23.1 \%)$ \\
\hline Pleural effusion & $2(5.9 \%)$ & $1(5.3 \%)$ & $1(7.7 \%)$ \\
\hline $\begin{array}{l}\text { No pneumonia or } \\
\text { pleural effusion }\end{array}$ & $5(14.7 \%)$ & $5(26.3 \%)$ & \\
\hline Pulmonary sequelae & $3(8.8 \%)$ & $3(15.8 \%)$ & \\
\hline Normal X-ray & $2(5.9 \%)$ & $2(5.9 \%)$ & \\
\hline
\end{tabular}

* 5/39 patients did not have an X-ray of which 4 were severe on admission; onset of symptoms could not be documented in $2 / 34$ patients, ${ }^{* *} P>0.05$ between acute and chronic melioidosis 
$\mathrm{p}<0.01)$. Overall fatality rate was of $61.5 \%(24 / 39)$; $45.8 \%(11 / 24)$ died during admission. Among the deceased, 23 (96\%) patients died without having received any of the active drugs (i.e. cotrimoxazole, chloramphenicol, doxycycline, amoxicillin-clavulanate acid). The pregnant woman died 5 days after discharge; all pediatric cases died at hospital. The 2 month-old child's mother could not be found to assess the potential routes of transmission. The median time from hospital admission to death was 3 days (range 1 - 61 days). Fatality was significantly higher in severe cases $(100 \%(11 / 11)$ vs. $46.4 \%(13 / 28) ; \mathrm{p}<0.01)$. There were no differences in fatality or severity between acute and chronic cases. Positive blood culture (21/24 (87.5\%) vs. $3 / 15$ (20\%); p < $0.01)$ and none active drug prescribed (23/26 (88.5\%) vs. $1 / 13(7.7 \%) ; \mathrm{p}<0.001)$ were also significantly associated with a higher fatality.

\section{Follow-up visits}

Of the 28 patients who were discharged, 24 could be located and visited; only 11 (45.8\%) remained alive. Of these $11,8(72.7 \%)$ attended follow-up consultations as recommended. Nine received a treatment with at least 2 active antibiotics after hospital discharge, of which seven interrupted antibiotics treatment complaining about the side effects or lack of money. Nevertheless all improved and were considered as cured during the second followup visit (median 567 days after discharge, range 420 1028). Chest X-rays were done at the time of the second visit in 9 patients who were initially admitted with radiographic evidence of pneumonia or pleural effusions. The results showed radiographic recovery (normal chest $\mathrm{X}$-ray) in four patients while the remaining five had radiographic imaging of lung sequelae.

\section{Costs}

The mean reported cost of the disease was 2,261,378 Riels (US\$565; range \$25-\$5000) including hospital costs, treatment costs and other related costs, such as food or transportation. Almost two thirds of the patients $(61.5 \%, \mathrm{n}=24 / 39)$ had to incur debt (range US\$150$1000)$; a third $(28.2 \%, \mathrm{n}=11 / 39)$ sold a cow, buffalo, pig or poultries and a quarter $(25.6 \%, \mathrm{n}=10 / 39)$ other belongings (gold or land).

\section{Discussion}

This report describes patients with pulmonary melioidosis, detected through surveillance of ALRI. To our knowledge, this is the first report of pulmonary melioidosis cases that were followed several months after hospital discharge in Cambodia [12-14].

Fatality rates $(\sim 62 \%)$ in our cohort were high compared to that of Thailand $(40.5 \%$ in 2006) $[2,16]$. These high rates likely were related to multiple factors, including inadequate antibiotic therapy, low awareness of the disease and limited access to health care services rather than a severity of the disease that is peculiar to Cambodia.

Indeed, awareness of melioidosis among health professionals remains low. In the context of high TB endemicity and low microbiological capacity in public hospitals, misdiagnosis of melioidosis taken as TB may not be uncommon [13]. All the more when six patients' chest $\mathrm{X}$-rays were interpreted as TB-like infection by our clinical experts. In the surveillance study, many clinicians did not account for melioidosis in their first line antibiotic treatment when diagnosing severe pneumonia. Moreover, many patients were discharged before having received bacteriological results; it is recognized in Cambodia that many patients' families would rather go back home if they cannot afford to stay longer at the hospital or when patients are severely ill with little hope of cure.

The turning point in the treatment of bacteremic melioidosis was the use of ceftazidime reducing by half fatality $[1,17]$. Parenteral co-amoxiclav would have been a cheaper alternative in our study hospital; unfortunately, both drugs are costly and not available in the National Essential Drugs list. With a potentially high burden of melioidosis in Cambodia (12 - 14), one should consider making ceftazidime available by using a generic form that is now manufactured in Thailand (http:// www.drugs.com/international/cef-4.html). Notably, oral treatment can still rely on cotrimoxazole - a cheap and available drug - as susceptibility testing for this antibiotic using E-test method has demonstrated no resistance of $B$. pseudomallei isolates. This finding contrasts with that of Northern Thailand where susceptibility of isolates was lower at $87 \%$ [18].

The present study showed that melioidosis had a substantial financial impact on households in rural Cambodia. To pay for these costs, two-thirds of households had to borrow money and $25 \%$ had to sell assets or use their savings, a finding that is consistent with studies on cost-of-illness for other infectious diseases in Cambodia [19]. To put in perspective, the average cost of melioidosis was similar to the Gross National Income per capita in Cambodia, i.e. US\$600 in 2008 [20]. These costs were overwhelming when compared to an average one-week expenditure on food of US\$ 9.5 per household [19].

Previous series reported 37 to $60 \%$ of diabetes mellitus in patients with melioidosis [5]. Only one study has documented a high prevalence of diabetes mellitus $(\sim 61 \%)$ in the sub-group of pulmonary melioidosis [16]. Our results were consistent with that of studies which reported higher prevalence of diabetes mellitus in bacteremic patients [21-23]. However, the proportion of diabetes mellitus in our series appeared low. This is surprising as the prevalence of diabetes mellitus in 

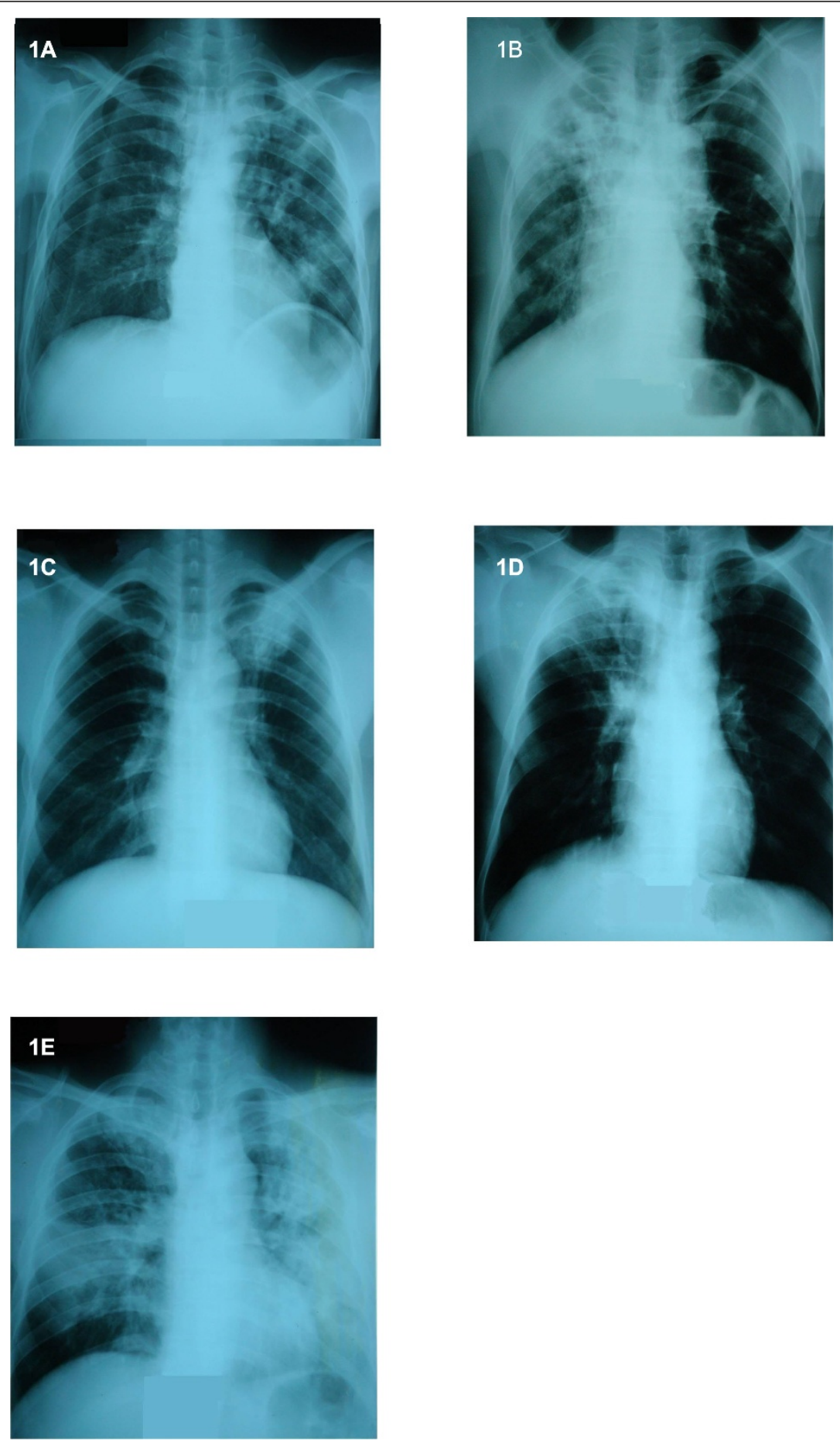

Figure 1 Chest radiographs evoking tuberculosis in 5 patients with pulmonary melioidosis. A: 48 year-old male; B: 52 year-old male; C: 52 year-old male who had a positive smear for acid-fast bacilli; D, 36 year-old male; E, 43 year-old male

Cambodia is thought to be high, accounting for $11 \%$ of the population in Kampong Cham province [24]. Similarly, we observed that severe patients were less likely to have co-morbidities. Diabetes mellitus may have been under-reported among our patients. Since most of these patients died quickly after their admission, it is possible that clinicians were less demanding when interrogating the family on diabetes as an underlying condition.

Our study has additional limitations. Estimating the extent of melioidosis and its severity in ALRI is 
problematic due to the difficulties in obtaining microbiological diagnoses. Few of our patients were children in whom sputum was difficult to collect and therefore hardly available. However, it is very likely that fewer children suffer from pulmonary melioidosis $[5,12]$. In Thailand, higher incidence rates were found in 40-60 year old adults [21]. In addition, blood culture is rarely positive in children since they suffer from less severe forms of melioidosis [5]. Of note, one patient was 2 months old at the time of diagnosis suggesting possible vertical transmission from mother to child or a neonatal infection [25]. Unfortunately, we could not trace this child for the follow-up investigation. Two of the three children died and were co-infected by H3N2 influenza virus. It is difficult indeed to relate the severity of the disease to influenza infection, although reactivation of melioidosis following influenza infection has been described in adults [26].

Second, the surveillance study is limited to hospitalized cases of pulmonary infection and so does not include sub-acute forms and other presentations of the disease; the follow-up questionnaire revealed that one third of the patients actually had chronic melioidosis which resulted in overestimating the proportion of melioidosis in severe acute respiratory infections. Nevertheless, we believe that our series is reasonably representative of people in the provinces as our hospitals were the only reference hospitals for their respective provinces.

\section{Conclusions}

We suggest, therefore, that pulmonary melioidosis should be considered in every patient with TB-like chest X-rays and negative AFB smears in Cambodia. The study was able to highlight difficulties faced by Cambodian clinicians when managing and treating melioidosis cases. In addition, it is imperative that Cambodian health professionals understand melioidosis and consider the disease in their differential diagnoses, especially for pulmonary tuberculosis and almost all other febrile infections, particularly during the rainy season. In the meantime, detecting B. pseudomallei in an endemic area could actually be implemented with the use of throat swabs. This method with $100 \%$ specificity (but low sensitivity, 36\%) could be easily disseminated to Cambodian hospitals [27]. Furthermore, strengthening hospital laboratories throughout Cambodia with an easy-to-make Ashdown's culture medium could be easily implemented [28]. These two recommendations taken together would provide further information on the burden of melioidosis in the different provinces in Cambodia and subsequently help advocate for the adoption of a national treatment protocol including ceftazidime.

\section{Acknowledgements}

We specifically acknowledge the patients for their participation to this study We are grateful to Dr Phat, Dr Mam, Dr Me, Dr Ya, Dr Koy, Dr Teav, Dr Ke, Dr Phea, Dr Chroeng, Dr Kim, Dr Iv, Dr Kheang, Dr Phe, Dr Chhav, Dr Ean, Dr leang for their contribution to this study and for patients' care. Surveillance and Investigation of endemic situations in South-East Asia (SISEA) is funded by the French Agency for Development (Agence Française de

Développement, AFD) and the US Department of Human and Health Services (US DHHS). Blandine Rammaert and Julien Beauté both received a grant from the Fondation Pierre Ledoux Jeunesse Internationale and Blandine Rammaert a grant from the Société de Pathologie Infectieuse de Langue Française.

\section{Author details}

${ }^{1}$ Institut Pasteur - Cambodia, Phnom Penh, Cambodia. ${ }^{2}$ Swiss Red Cross, Takeo, Cambodia. ${ }^{3}$ Donkeo Provincial Hospital, Takeo, Cambodia. ${ }^{4}$ Kampong Cham Provincial hospital, Kampong Cham, Cambodia. ${ }^{5}$ Centre de pneumologie et réanimation respiratoire, Hôpital Tenon, Paris, France.

\section{Authors' contributions}

$C A, S V, B G, L B, R O, P B, B R$ and $C M$ contributed to the design of the study, conducted the study, participated in statistical analysis and interpretation of data, and manuscript preparation. VT, PLT, SG, SH, CA, BR, RO gathered the secondary and collected the data from the field. $B R, J B, L B$ analyzed the data and wrote the first draft of the manuscript. SV, CA and BG conceived the study. SV and BG as senior authors contributed equally to this study and approved the final version of the manuscript. All authors read and approved the final manuscript.

\section{Competing interests}

The author declares that they have no competing interests.

Received: 22 November 2010 Accepted: 14 May 2011

Published: 14 May 2011

\section{References}

1. White NJ: Melioidosis. Lancet 2003, 361:1715-1722.

2. Limmathurotsakul D, Wongratanacheewin S, Teerawattanasook N, Wongsuvan G, Chaisuksant S, Chetchotisakd P, Chaowagul W, Day NP, Peacock SJ: Increasing incidence of human melioidosis in Northeast Thailand. Am J Trop Med Hyg 2010, 82:1113-7.

3. Currie BJ, Ward L, Cheng AC: The epidemiology and clinical spectrum of melioidosis: 540 cases from the 20 year darwin prospective study. PLoS Negl Trop Dis 2010, 4:e900.

4. Dance DAB: Melioidosis. Curr Opin Infect Dis 2002, 15:127-132.

5. Cheng AC, Currie BJ: Melioidosis: epidemiology, pathophysiology, and management. Clin Microbiol Rev 2005, 18:383-416.

6. Kanaphun $P$, Thirawattanasuk N, Suputtamongkol $Y$, Naigowit $P$, Dance DA, Smith MD, White N: Serology and carriage of Pseudomonas pseudomallei: a prospective study in 1000 hospitalized children in northeast Thailand. J Infect Dis 1993, 167:230-233.

7. Currie BJ, Fisher DA, Howard DM, Burrow JN, Lo D, Selva-Nayagam S, Anstey NM, Huffam SE, Snelling PL, Marks PJ, Stephens DP, Lum GD, Jacups SP, Krause VL: Endemic melioidosis in tropical northern Australia: a 10-year prospective study and review of the literature. Clin Infect Dis 2000, 31:981-986.

8. Dance DA: Melioidosis as an emerging global problem. Acta Trop 2000, 74:115-119.

9. Wuthiekanun V, Chierakul W, Langa S, Chaowagul W, Panpitpat C, Saipan P, Thoujaikong T, Day NP, Peacock SJ: Development of antibodies to Burkholderia pseudomallei during childhood in melioidosis-endemic northeast Thailand. Am J Trop Med Hyg 2006, 74:1074-1075.

10. White NJ, Dance DA, Chaowagul W, Wattanagoon Y, Wuthiekanun V, Pitakwatchara N: Halving of mortality of severe melioidosis by ceftazidime. Lancet 1989, 2:697-701.

11. Chan KPW, Low JGH, Raghuram J, Fook-Chong SMC, Kurup A: Clinical characteristics and outcome of severe melioidosis requiring intensive care. Chest 2005, 128:3674-3678.

12. Pagnarith $Y$, Kumar V, Thaipadungpanit J, Wuthiekanun V, Amornchai $P$, Sin L, Day NP, Peacock SJ: Emergence of pediatric melioidosis in Siem Reap, Cambodia. Am J Trop Med Hyg 2010, 82:1106-1112. 
13. Overtoom R, Khieu V, Hem S, Cavailler P, Te V, Chan S, Lau P, Guillard B, Vong S: A first report of pulmonary melioidosis in Cambodia. Trans $R$ SoC Trop Med Hyg 2008, 102:S21-25.

14. Wuthiekanun V, Pheaktra N, Putchhat $H$, Sin L, Sen B, Kumar V, Langla S, Peacock SJ, Day NP: Burkholderia pseudomallei antibodies in children Cambodia. Emerging Infect Dis 2008, 14:301-303.

15. World Health Organization: Pocket book of Hospital Care for Children. Guidelines for the management of common illenesses with limited ressources. World Health Organization. Geneva; 2006.

16. Mukhopadhyay A, Lee KH, Tambyah PA: Bacteraemic melioidosis pneumonia: impact on outcome, clinical and radiological features. $J$ Infect 2004, 48:334-338.

17. Simpson AJ, Suputtamongkol Y, Smith MD, Angus BJ, Rajanuwong A, Wuthiekanun V, Howe PA, Walsh AL, Chaowagul W, White NJ: Comparison of imipenem and ceftazidime as therapy for severe melioidosis. Clin Infect Dis 1999, 29:381-7.

18. Wuthiekanun V, Cheng AC, Chierakul W, Amornchai P, Limmathurotsakul D, Chaowagul W, Simpson AJ, Short JM, Wongsuvan G, Maharjan B, White NJ, Peacock SJ: Trimethoprim/sulfamethoxazole resistance in clinical isolates of Burkholderia pseudomallei. J Antimicrob Chemother 2005, 55:1029-31.

19. Huy R, Wichmann O, Beatty M, Ngan C, Duong S, Margolis HS, Vong S: Cost of dengue and other febrile illnesses to households in rural Cambodia: a prospective community-based case-control study. BMC Public Health 2009, 9:155.

20. Cambodia data of the World Bank:[http://data.worldbank.org/country/ cambodia], [Accessed June 28, 2010]..

21. Suputtamongkol Y, Chaowagul W, Chetchotisakd P, Lertpatanasuwun N, Intaranongpai S, Ruchutrakool T, Budhsarawong D, Mootsikapun P, Wuthiekanun V, Teerawatasook N, Lulitanond A: Risk factors for melioidosis and bacteremic melioidosis. Clin Infect Dis 1999, 29:408-413.

22. Chaowagul W, White NJ, Dance DA, Wattanagoon Y, Naigowit P, Davis TM, Looareesuwan S, Pitakwatchara N: Melioidosis: a major cause of community-acquired septicemia in northeastern Thailand. $J$ Infect Dis 1989, 159:890-899.

23. Puthucheary SD, Parasakthi N, Lee MK: Septicaemic melioidosis: a review of 50 cases from Malaysia. Trans R Soc Trop Med Hyg 1992, 86:683-685.

24. King H, Keuky L, Seng S, Khun T, Roglic G, Pinget M: Diabetes and associated disorders in Cambodia: two epidemiological surveys. Lancet 2005, 366:1633-1639

25. Abbink FC, Orendi JM, de Beaufort AJ: Mother-to-child transmission of Burkholderia pseudomallei. N Engl J Med 2001, 344:1171-1172.

26. Mackowiak PA, Smith JW: Septicemic melioidosis. Occurrence following acute influenza A six years after exposure in Vietnam. JAMA 1978, 240:764-766.

27. Wuthiekanun V, Suputtamongkol Y, Simpson AJ, Kanaphun P, White NJ: Value of throat swab in diagnosis of melioidosis. J Clin Microbiol 2001, 39:3801-3802.

28. Walsh AL, Wuthiekanun $\mathrm{V}$ : The laboratory diagnosis of melioidosis. $\mathrm{Br}$ Biomed Sci 1996, 53:249-53.

\section{Pre-publication history}

The pre-publication history for this paper can be accessed here: http://www.biomedcentral.com/1471-2334/11/126/prepub

\section{doi:10.1186/1471-2334-11-126}

Cite this article as: Rammaert et al:: Pulmonary melioidosis in Cambodia: A prospective study. BMC Infectious Diseases 2011 11:126.

\section{Submit your next manuscript to BioMed Central and take full advantage of:}

- Convenient online submission

- Thorough peer review

- No space constraints or color figure charges

- Immediate publication on acceptance

- Inclusion in PubMed, CAS, Scopus and Google Scholar

- Research which is freely available for redistribution

Submit your manuscript at www.biomedcentral.com/submit
Biomed Central 